\title{
The Effects of the Perception of Work-life Balance on Acceptance of Work Arrangement Requests
}

\author{
Yutaka Ueda ${ }^{1}$ \\ ${ }^{1}$ Faculty of Economics, Seikei University, Tokyo, Japan \\ Correspondence: Yutaka Ueda, Faculty of Economics, Seikei University, 3-3-1 Kichijoji-kitamachi, \\ Musashino-city, Tokyo 180-8633, Japan. Tel: 81-422-373-589. E-mail: ueda@econ.seikei.ac.jp
}

Received: April 3, 2012 Accepted: April 23, $2012 \quad$ Online Published: July 1, 2012

doi:10.5539/ibr.v5n8p24 URL: http://dx.doi.org/10.5539/ibr.v5n8p24

\begin{abstract}
Although social support provided by supervisors has been recognized as one of the key factors that help employees utilize work-life balance (WLB) programs in their organization and maintain balance between their work and life, the factors that influence supervisors' willingness to support their subordinates have not yet been sufficiently examined. This article investigated whether supervisors' positive or negative perceptions of WLB policy and their subordinate's past performance influenced supervisors' willingness to accept their subordinates' work arrangement requests, using data collected from 2,230 Japanese workers. The results showed that when supervisors had a positive perception of WLB policy, it positively influenced their acceptance of their subordinates' requests, while negative perceptions had a negative impact on acceptance. Further, regardless of what was requested, high performance subordinates received more favorable treatment from their supervisors than low performance counterparts did.
\end{abstract}

Keywords: work-life balance, social support, Japanese culture

\section{Introducation}

\subsection{Introduce the Problem}

Those with careers often struggle with the difficulty of fulfilling their responsibilities for both their work and family domains. Work-family conflict stemming from the inability to perform both duties leads often to negative outcomes for workers, such as reduced well-being and impaired health. Governments have emphasized the importance of employees keeping a good balance between work and life, and many businesses and organizations have introduced various work-life balance (WLB) programs to help change employees' work arrangements. For example, Japan was once considered a country of severe workaholics, but the Japanese government established the Charter of Work-Life Balance in 2007, in order to encourage Japanese organizations and people to address the need to improve the WLB of workers in Japan. Employees who needed to fulfill familial obligations were encouraged to ask their organization to change their work arrangements, such as reducing their working hours, exempting them from overtime, and allowing temporary leave for childcare.

However, merely introducing WLB programs into organizations is not sufficient to make employees positively utilize them to improve their WLB. For example, using a survey, Matsuda, Kokumai, and Wang (2009) found that conservative attitude or atmosphere at the workplace to WLB programs and activities, management does not appreciate the value of WLB, and male employees do not appreciate the value of WLB inhibited WLB implementation, rather than a flaw in the WLB policy of the organization. Further, de Villiers and Kotze's (2003) qualitative study found that the most significant work-life conflicts arise from complex workplace issues, such as management change, supervisory and technical competences, leadership, roles and accountabilities, and culture. They said that, "the results suggest that leadership, supervisor/manager recognition and support for individuals and their needs, influence work-life balance" (de Villiers \& Kotze, 2003, p. 22).

In fact, among the factors outside an organization's defined WLB program, the social support from supervisors has been found to be both necessary and effective in the improvement of employees' WLB. Researchers have emphasized the importance of social support from supervisors in helping employees decrease work-life conflict and enhance job satisfaction (Casper, Harris, Taylor-Bianco, \& Wayne, 2011; Rani, Kamalanabhan, \& Selvarani, 
2011; Michael, Mitchelson, Pichler, \& Cullen, 2010; Schirmer \& Lopez, 2001; Seiger \& Wiese, 2009; Thomas \& Ganster, 1995; van Daalen, Willemsen, \& Sanders, 2006). However, the factors that influence supervisors' willingness to support their subordinates have received little attention so far. This article focused on two factors of supervisors' willingness to support subordinates. Specifically, it focused on the effects of supervisors' perceptions of WLB policy and subordinates' past performance on supervisors' willingness to accept requests from subordinates, regarding changes in their work arrangement due to family matters.

\section{Supervisory Support and Its Antecedents}

In the work-family literature, social support has been found to be one of the key factors that help reduce work-family conflict (Matthews, Bulger, \& Barnes-Farrell, 2010; Seiger \& Wiese, 2009). Social support involves "providing empathy, care, love and trust (emotional support), actual aide in time, money and energy (instrumental support), information relevant to self-evaluation (appraisal support), and advice, information and suggestions (information support)" (van Daalen et al., 2006, p. 464). In addition, according to Michael et al. (2010), work social support (family social support) is defined as, "instrumental aid, emotional concern, informational, and appraisal functions of others in the work (family) domain that are intended to enhance the well-being of the recipient" (Michael et al., 2010, p. 92).

Although each organization has their own work-family policy and culture, supervisors tend to play a "gatekeeper" role in the utilization of WLB programs (Muse \& Pichler, 2011). In this context, employees' perception of supervisory support is defined as their "general views about the degree to which their supervisors value their contribution and care about their well-being" (Casper et al., 2011, p. 644).

Supervisory support has been found to have a positive impact on employee perception and attitude regarding their WLB. For example, based on data from 210 respondents working in IT organizations, Rani et al. (2011) found that not only the nature of work tasks but also superior-subordinate relationships influenced WLB, which, in turn, influenced employee satisfaction. Further, Thomas and Ganster (1995) considered the importance of the role of the supportive supervisor who "emphasizes with the employee's desire to seek balance between work and family responsibilities" (Thomas \& Ganster, 1995, p. 7). Schirmer and Lopez (2001) also found supervisor support predicted low work stress intensity, low symptomatic distress, and high job satisfaction using data from a university employee sample. Seiger and Wiese (2009) found that supervisory social support was negatively related to work-family conflict (WFC), although Van Daalen et al. (2006) found that this relationship was moderated by gender. Casper et al.'s (2011) results showed that perceived supervisor support influenced employees' affective commitment, and Michael et al. (2010) found that work social support, including leader/manager support, was negatively related to role conflict, time demands, and role ambiguity in the work domain.

In this article, we particularly focused on the aspect of supervisory social support called "willing acceptance," where supervisors readily accept the requests of employees who hope to change their work arrangements, in order to decrease their workplace burdens and promote their WLB. This aspect of social support is critical because often employees become discouraged in asking about work arrangements, especially if they know that their supervisor hesitates in accepting them.

One might ask why supervisors' willingness to accept requests from their subordinates matters; it only matters whether the employee has completed the proper procedures involved, and the supervisor's own willingness is irrelevant. However, it is true that an employee's absence, regardless of their actual work performance, can be regarded as demonstrating inferior performance or disloyalty. For example, with regards to the presenteeism culture in the workplace, Watts (2009) described, "the way that work 'flexibility' was used implied, in the main, an availability and willingness to stay at work as long as necessary and those who could not conform to this expectation were regarded as less loyal and certainly less committed" (Watts, 2009, pp. 45-46). When employees' ask about work arrangements such as reducing working hours, it might be seen by employers or supervisors as a "red flag" that shows these employees' inferiority or disloyalty to the organization (Amilton, 2010). Therefore, it is quite important for employees to know if their employers will willingly accept their work arrangement requests, or if they hesitate despite it being a legal claim.

Although supervisory social support is emphasized as key in the promotion of WLB in employees, only a few researchers have focused on the antecedent of social support-willingness-from supervisors (Bowling, Beehr, \& Swader, 2005; Waters, 2004). In many cases, the social support for employees is not regarded as a formal responsibility of supervisors; rather, supervisors use discretion in determining how positively they support others. In this regard, we focused on two factors that have been considered to affect willing acceptance: Supervisors' 
perception of their organization's WLB policy, and subordinates' past performance.

The first factor is the effect of supervisors' perceptions. Although everyone generally recognizes WLB policy as necessary, and contributive to the well-being of employees, supervisors' evaluations of WLB policy and WLB programs in their organization are not always positive; they know that employees often work in teams, and the performance of other employees will be affected if one employee's work arrangements are changed. Thus, some supervisors believe that WLB policy disrupts the peace of a workplace, and show these negative views through their behavior in dealing with their subordinates. For example, Sakazume (2009) found that a manager's positive or negative perceptions of WLB practice influenced his or her leadership behaviors.

Therefore, supervisors' perceptions of WLB policy are considered to influence how they respond to their subordinates' work arrangement requests. If they have a positive perception of WLB policy, they tend to accept more willingly subordinates' requests. In contrast, when they have a negative perception of WLB policy, they tend to hesitate in accepting, or, if possible, try to reject the request.

Hypothesis 1 (H1). Supervisors will more likely accept subordinates' work arrangement requests when they have a positive perception of WLB policy than when they do not.

Hypothesis 2 (H2). Supervisors will less likely accept subordinates' work arrangement requests when they have a negative perception of WLB policythan when they do not.

The second factor is the effect of a subordinate's past performance if they seek to benefit from a work arrangement change. When Bowling et al. (2005) stated, "providing others with social support can be considered a contribution, whereas receiving social support can be considered a benefit" (Bowling et al., 2005, p. 479), they emphasized the importance of a reciprocal relationship between employees in determining the amount of social support given and received in the relationships between co-workers. Although the same reciprocal relationship is also expected between supervisors and subordinates, supervisors' perspectives might differ from those of co-workers, in that they perceive the work arrangement benefits as gifts that they give to employees. For example, Matthews et al. (2010) more widely defined work social support as "a form of social support that helps individuals accomplish their work" (Matthews et al., 2010, p. 78). Supervisors and subordinates work interactively in a vertical hierarchy, and if subordinates are successful in producing high performance, their supervisors perceive such high performance as supporting their own management ability, and thus as accomplishing their own work. Therefore, we assume that supervisors tend to consider that high performance employees make very important contributions to them and their organization, and thus are more eligible to gain work arrangement benefits and receive social support. In contrast, they might also consider poor performance employees are less worthy of gaining such benefits, and thus they are less likely to give social support to these employees. This argument is summarized in the following hypothesis.

Hypothesis 3 (H3). Supervisors will more likely accept these subordinates' work arrangement requests when they know subordinates have attained high performancethan when they know subordinates have attained low performance.

\section{Method}

\subsection{Sample and Database}

Data from "The Survey Regarding Work-Life Balance, 2008" were used for this study. This survey was conducted by the Research Institute for Advancement of Living Standards (RIALS) in August 2008, which offered the data to the Social Science Japan Data Archive, Center for Social Research and Data Archives, Institute of Social Science, The University of Tokyo, in order to provide academic researchers with an opportunity to receive and analyze it. Respondents consisted of Japanese full-fledged workers at a number of companies, who originally registered their names as voluntary respondents for an online company named Macromill Inc. Macromill Inc. judged how many respondents would be needed in the age and company brackets, according to statistical information regarding Japanese employment structures in 2002, and asked registered workers to respond to the questionnaire. The total number of respondents was 2,230, with 1,557 (69.8\%) males, and $673(30.2 \%)$ females, with an average age of 39.39 years old.

\subsection{Measures}

The means of responses to multiple items from the RIALS survey were calculated and utilized as independent and dependent variables.

Independent variables. The two independent variables were indicators of supervisors' positive and negative 
perceptions of corporate WLB policy. "Positive perception of WLB policy" was constructed from the means of five items from the original survey $(\alpha=0.858)$. The exemplary items included, "(WLB is) necessary to secure qualified human resources" and "(WLB) contributes to improving the morale of employees." "Negative perception of WLB policy" was developed from the means of three items from the original survey $(\alpha=0.703)$. The exemplary item was, "(WLB) imposes a heavy burden on a company." All of these items were measured with a four-point scale ranging from [1], "do not agree," to [4], "agree."

Dependent variables. The six dependent variables served as indicators of supervisors' reactions to subordinates' work arrangement requests. The first four variables were associated with two different requests regarding work arrangements and two different performance levels of subordinates. The original questionnaire included twelve items with four-point scales ranging from [1], "unacceptable," to [4], "no problem (acceptable)," which revealed the high or low performance subordinates' (hereafter, referred to high performers and low performers) requests for various work arrangements to supervisors. Then, four sets of three items were regarded as representative of four $(2 \times 2)$ situations: High or low performers asking to change their work arrangements by reducing their regular working hours or exempting them from overtime work because of family matters. Comparing the two requests, work arrangements regarding overtime might be more easily accepted than those regarding reducing regular working hours, because working overtime is considered more discretionary than working during ordinary hours. The Cronbach's alpha values for these four variables ranged from 0.850 to 0.895 , which showed they had sufficient internal consistency. Respondents were not necessarily in a management position, and if they were not, they were encouraged to assume they had been a manager when answering the questionnaire.

The remaining two variables were used to determine whether there was a difference in dealing with subordinates who required the same work arrangements but performed differently. The variables were created by subtracting the response to a question regarding low performers from a response for high performers. If these variables were close to zero, the supervisors were considered to respond similarly to requests from subordinates regardless of who required it. In contrast, the positive value of the variables means that supervisors deal with the high performers more favorably than with low performers.

Control variables. Gender ([1], "male," or [2], "female"), age (real), educational background (six-point scale ranging from [1], "junior high school," to [6], "graduate school"), company size as measured by the number of employees (seven-point scale ranging from [1], "under 29," to [7], "over 3,000"), labor union (1, "exists" or 2, "non-existent"), and annual income (seven-point scale ranging from [1], "under 3,000,000 Japanese yen," to [7], "over 10,000,000 Japanese yen"), were used as control variables for this study.

\section{Results}

\subsection{Means, Standard Deviations, Reliabilities, and Inter-correlations regarding Variables}

Table 1 shows the means, standard deviations (std. dev.), reliabilities (Cronbach's alpha values), and inter-correlations regarding the control, independent, and dependent variables. Among the variables, "high minus low, reducing working hours (or exempting overtime)" values were formed by subtracting the degree of acceptance to low performers' requests from the degree of acceptance to high performers' requests for reducing working hours (or exempting overtime). Based on t-test scores, these two values were significantly different from zero $(t=4.691$, for reducing working hours, $t=11.896$, for exempting overtime), which showed that respondents had a greater tendency to accept requests from high performers than from low performers.

One of the most interesting findings regarding the correlations of control variables was that some control variables had both positive and negative correlations with a dependent variable. For example, the correlation between gender and acceptance to low performers' requests for exempting overtime was significantly negative $(\gamma$ $=-.053, \mathrm{p}<.05)$, while all other correlations between gender and the remaining dependent variables were significantly positive. Similarly, only the correlation between age and low performers' requests for exempting overtime was significantly negative $(\gamma=-.048, \mathrm{p}<.05)$, while all other correlations of age and the remaining dependent variables were positive. Further, annual income had a negative correlation with high performers' requests for reducing time $(\gamma=-.052, \mathrm{p}<.05)$, while other correlations of income and the remaining dependent variables were positive.

As for correlations between the independent variables and dependent variables, positive perception of WLB had positive significant correlations with all four dependent variables, while negative perception of WLB has negative significant correlations with the same variables. These results supported $\mathrm{H} 1$ and $\mathrm{H} 2$. However, none of the correlations between perception of WLB and differences in acceptances was significant. 
Table 1. Means, Standard Deviations, Reliabilities (Cronbach's alphas), and Inter-correlations regarding Variables

\begin{tabular}{|c|c|c|c|c|c|c|c|c|c|c|c|c|c|c|c|c|}
\hline & Variables & Means & Std. dev. & $\mathrm{N}$ & 1 & 2 & 3 & 4 & 5 & 6 & 7 & 8 & 9 & 10 & 11 & 12 \\
\hline 1 & Gender & 1.300 & .459 & 2230 & & & & & & & & & & & & \\
\hline 2 & Age & 39.390 & 10.143 & 2230 & $-.110^{* *}$ & & & & & & & & & & & \\
\hline 3 & Educational background & 3.860 & 1.399 & 2228 & $-.068^{* *}$ & $-.157^{* *}$ & & & & & & & & & & \\
\hline 4 & Labor union & 1.700 & .549 & 2230 & $.080^{* *}$ & $-.099^{* *}$ & $-.090^{* *}$ & & & & & & & & & \\
\hline 5 & Annual income & 3.140 & 1.690 & 2216 & $-.386^{* *}$ & $.386^{* *}$ & $.209^{* *}$ & $-.285^{* *}$ & & & & & & & & \\
\hline 6 & $\begin{array}{l}\text { Positive perception } \\
\text { of WLB }\end{array}$ & 3.288 & .521 & 2230 & $.061^{* *}$ & $-.116^{* *}$ & $.054^{*}$ & .026 & -.040 & $(.853)$ & & & & & & \\
\hline 7 & $\begin{array}{l}\text { Negative perception } \\
\text { of WLB }\end{array}$ & 2.592 & .618 & 2230 & .024 & $-.059^{* *}$ & -.039 & -.007 & $-.049^{*}$ & $.160^{* *}$ & $(.703)$ & & & & & \\
\hline 8 & $\begin{array}{l}\text { High performer, } \\
\text { reducing working hours }\end{array}$ & 3.151 & .613 & 2230 & $.131^{* *}$ & $-.093^{* *}$ & $.088^{* *}$ & $-.089^{* *}$ & .025 & $.160^{* *}$ & $-.110^{* *}$ & $(.850)$ & & & & \\
\hline 9 & $\begin{array}{l}\text { High performer, } \\
\text { exempting overtime }\end{array}$ & 2.837 & .816 & 2230 & -.005 & .028 & $.042^{*}$ & $-.062^{* *}$ & $.083^{* *}$ & $.095^{* *}$ & $-.117 * *$ & $.408^{* *}$ & $(.872)$ & & & \\
\hline 10 & $\begin{array}{l}\text { Low performer, } \\
\text { reducing working hours }\end{array}$ & 3.104 & .703 & 2230 & $.070^{* *}$ & $-.048^{*}$ & $.087^{* *}$ & $-.102^{* *}$ & $.058^{* *}$ & $.152^{* *}$ & -.104 & $.742^{* *}$ & $.366^{* *}$ & $(.891)$ & & \\
\hline 11 & $\begin{array}{l}\text { Low performer, } \\
\text { exempting overtime }\end{array}$ & 2.687 & .918 & 2230 & $-.053^{*}$ & $.084^{* *}$ & $.047^{*}$ & $-.097^{* *}$ & $.113^{* *}$ & $.064^{* *}$ & $-.100^{* *}$ & $.300^{* *}$ & $.770^{* *}$ & $.508^{* *}$ & (.895) & \\
\hline 12 & $\begin{array}{l}\text { High minus low, } \\
\text { reducing working hours }\end{array}$ & .048 & .480 & 2230 & $.064^{* *}$ & $-.048^{*}$ & -.015 & .036 & $-.052^{*}$ & -.018 & 0.012 & $.190^{* *}$ & -.016 & $-.517^{* *}$ & $-.361^{* *}$ & \\
\hline 13 & $\begin{array}{l}\text { High minus low, } \\
\text { exempting overtime }\end{array}$ & .150 & .596 & 2230 & $.075^{* *}$ & $-.090^{* * *}$ & -.015 & $.065^{* *}$ & $-.060^{* *}$ & .031 & -.006 & $.096^{* *}$ & $.182^{* *}$ & $-.282^{* * *}$ & $-.487^{* *}$ & $.535^{* *}$ \\
\hline
\end{tabular}

\subsection{Hypotheses Testing: Result of Hierarchical Regression Analysis}

A hierarchical regression analysis was conducted to examine whether or not supervisors' perceptions of WLB had thehypothesized effects on their acceptance of requests. First, control variables such as gender, age, education background, labor union, and annual income were entered into the equation, and then perception of WLB wasadded into the equation in order to detect whether there was a significant increase inthe explanatory power of the equation.

Table 2 depicts the results of the hierarchical regression analysis, with the work arrangement requests for high performers as dependent variables. This table shows thestandardized partial regression coefficients (Beta), adjusted coefficients of determination ( $\left.\operatorname{adj~} \mathrm{r}^{2}\right)$, the change in coefficients of determination $\left(\Delta \mathrm{r}^{2}\right), \mathrm{F}$ values $(F)$, and the change in $F$ values $(\Delta F)$. According to this table, supervisors' acceptance did not differ depending on what arrangement was required by high performers. Specifically, supervisors' positive perception of WLB had a positive significant impact on their acceptance of high performers' requestsfor both reducing their working time $(\beta=.163, \mathrm{p}<.01)$ and exempting them from overtime $(\beta=.118, \mathrm{p}<.01)$, which supported H1. Further, the results also showed that supervisors' negative perception of WLB negatively influencedtheir acceptance of both of the high performers' requests, reducing working hours $(\beta=-.139, \mathrm{p}<.01)$, and exempting overtime $(\beta=$ $-.131, \mathrm{p}<.01)$. This also supported $\mathrm{H} 2$.

Table 2. Result of Hierarchical Regression Analysis (Acceptance of High Performers' Requests)

\begin{tabular}{|c|c|c|c|c|c|c|c|c|c|}
\hline \multirow{2}{*}{\multicolumn{2}{|c|}{ Models }} & \multicolumn{4}{|c|}{$\begin{array}{l}\text { High performers' request for reducing working } \\
\text { hours }\end{array}$} & \multicolumn{4}{|c|}{$\begin{array}{l}\text { High performers' request forexempting } \\
\text { overtime }\end{array}$} \\
\hline & & \multicolumn{2}{|c|}{ Beta } & $\begin{array}{l}\Delta \mathrm{r}^{2} \\
\left(\operatorname{adj~} \mathrm{r}^{2)}\right.\end{array}$ & $\begin{array}{l}\Delta F \\
(F)\end{array}$ & \multicolumn{2}{|c|}{ Beta } & $\begin{array}{l}\Delta \mathrm{r}^{2} \\
\left(\operatorname{adj~} \mathrm{r}^{2)}\right.\end{array}$ & $\begin{array}{l}\Delta F \\
(F)\end{array}$ \\
\hline \multirow[t]{5}{*}{1} & Gender & .167 & ${ }^{* * *}$ & & & .028 & & & \\
\hline & Age & -.111 & $* * *$ & & & .004 & & & \\
\hline & Educational background & .054 & $* *$ & & & .024 & & & \\
\hline & Labor union & -.079 & $* * *$ & .046 & $21.453^{* * *}$ & -.040 & * & .010 & $4.379^{* * *}$ \\
\hline & Annual income & .098 & $* * *$ & $(.044)$ & $(21.453)$ & .077 & $* * *$ & $(.008)$ & $(4.379)$ \\
\hline \multirow[t]{7}{*}{2} & Gender & .159 & ${ }^{* * *}$ & & & .023 & & & \\
\hline & Age & -.102 & ${ }^{* * *}$ & & & .009 & & & \\
\hline & Educational background & .041 & ${ }^{*}$ & & & .014 & & & \\
\hline & Labor union & -.086 & $* * *$ & & & -.045 & ** & & \\
\hline & Annual income & .091 & $* * *$ & & & .072 & $* * *$ & & \\
\hline & Positive perception of WLB & .163 & ${ }^{* * *}$ & .038 & $46.115^{* * *}$ & .118 & $* * *$ & .026 & $29.426^{* * *}$ \\
\hline & Negative perceptionof WLB & -.139 & *** & $(.082)$ & $(29.126)$ & -.131 & ${ }^{* * *}$ & $(.032)$ & $(11.616)$ \\
\hline
\end{tabular}

Note: $\mathrm{N}=2,230,{ }^{* * *}: \mathrm{p}<.01,{ }^{* *}: \mathrm{p}<.05,{ }^{*}: \mathrm{p}<.1$. 
Next, Table 3 shows the results of the hierarchical regression analysis forsupervisors' acceptance of low performers' requests. The results displayed in Table 3 are the same as those of Table 2: Supervisors' positive perception of WLB had a positive impact on their acceptance of requests for both reducing working time ( $\beta$ $=.161, \mathrm{p}<.01)$, and exempting overtime $(\beta=.091, \mathrm{p}<.01)$. Further, negative perceptions of WLB had a negative effect on their acceptance of requests for both reducing working time $(\beta=-.130, p<.01)$, and exempting overtime $(\beta=-.106, \mathrm{p}<.01)$. There were no differing effects of supervisors' perceptions on acceptance, no matter thetype of request. As a whole, Table 3's results also supported H1 and H2.

Table 3. Result of Hierarchical Regression Analysis (Acceptance to Low Performers' Requests)

\begin{tabular}{|c|c|c|c|c|c|c|c|c|c|}
\hline & & Low perforn & ers' & uest for 1 & g working hours & Low perfor & ners & quest for & apting overtime \\
\hline & dels & Beta & & & $\Delta F$ & Beta & & & $\Delta F$ \\
\hline & & & & & & & & & \\
\hline 1 & Gender & .109 & & & & -.016 & & & \\
\hline & Age & -.070 & *** & & & .060 & ** & & \\
\hline & Educational background & .057 & ** & & & .038 & * & & \\
\hline & Labor union & -.087 & *** & .030 & $13.705^{* * *}$ & -.070 & $* * *$ & .021 & $9.429^{* * *}$ \\
\hline & Annual income & .090 & $* * *$ & $(.028)$ & $(13.705)$ & .056 & $* *$ & $(.019)$ & $(9.429)$ \\
\hline 2 & Gender & .101 & $* * *$ & & & -.021 & & & \\
\hline & Age & -.060 & *** & & & .064 & *** & & \\
\hline & Educational background & .045 & $* *$ & & & .030 & & & \\
\hline & Labor union & -.093 & *** & & & -.074 & *** & & \\
\hline & Annual income & .084 & $* * *$ & & & .052 & ** & & \\
\hline & Positive perception of WLB & .161 & $* * *$ & .036 & $42.212^{* * *}$ & .091 & $* * *$ & .016 & $18.811^{* * *}$ \\
\hline & Negative perceptionof WLB & -.130 & $* * *$ & $(.063)$ & $(22.215)$ & -.106 & *** & $(.034)$ & $(12.218)$ \\
\hline
\end{tabular}

Note: $\mathrm{N}=2,230,{ }^{* * *}: \mathrm{p}<.01,{ }^{* *}: \mathrm{p}<.05,{ }^{*}: \mathrm{p}<.1$.

We initially had an interest in examining whether supervisors' willingness to acceptrequests would be different depending on who made the request. The four graphs in Figure 1 display the differing effects of positive or negative perception on supervisors' acceptance of requests, depending on their subordinates' performance (effect of positive perception on reducing working time onthe upperleft; effect of positive perception on exempting overtime on the upper right; effect of negative perception on reducing working time at the lowerleft; and the effect of negative perception on exempting overtime atthe lowerright), using the values of the unstandardized partial regression coefficients of the perceptions and constants. Except for the graph on the upper-left, these graphs also depict, as shown in Table 1, that high performers tend tohave their requests accepted more often by supervisors than lower performers, as hypothesized in $\mathrm{H} 3$.
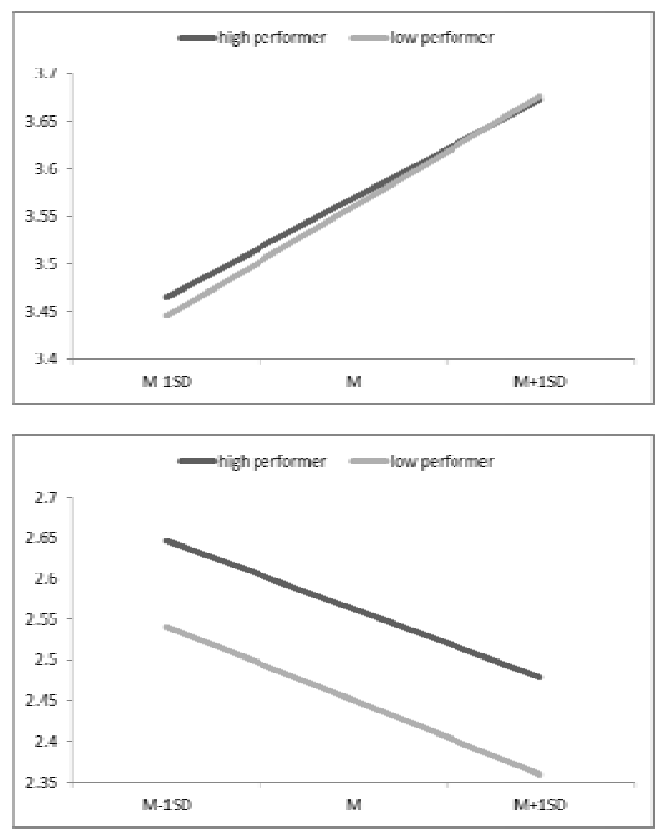
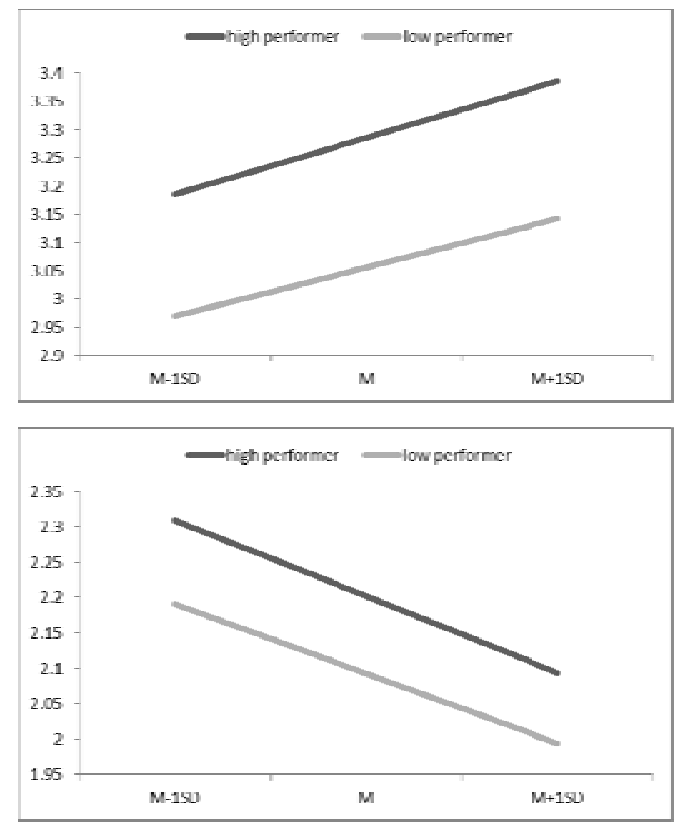

Figure 1. Effect of Perception of WLB on Acceptance to Requests 
In the upper-left graph, the differences in acceptance for high and low performers appear to change depending on the change in their supervisors' positive or negative perception of WLB; in the other graphs, the differences between them appear mostly unchanged. In order to further examine the effect of supervisors' perception of WLB on these differences, we conducted a similar hierarchical regression analysis with the differences between supervisors' acceptance of requests from high and low performers as dependent variables. The results of this analysis are shown in Table 4. According to this table, there were no significant effects of supervisors' perception of WLB on these differences, andwe can therefore conclude that simple interaction effects of supervisors' perception of WLB and subordinates' performance on supervisors' acceptance were not observed.

Table 4. Result of Hierarchical Regression Analysis (Difference of Acceptances between High and Low Performers)

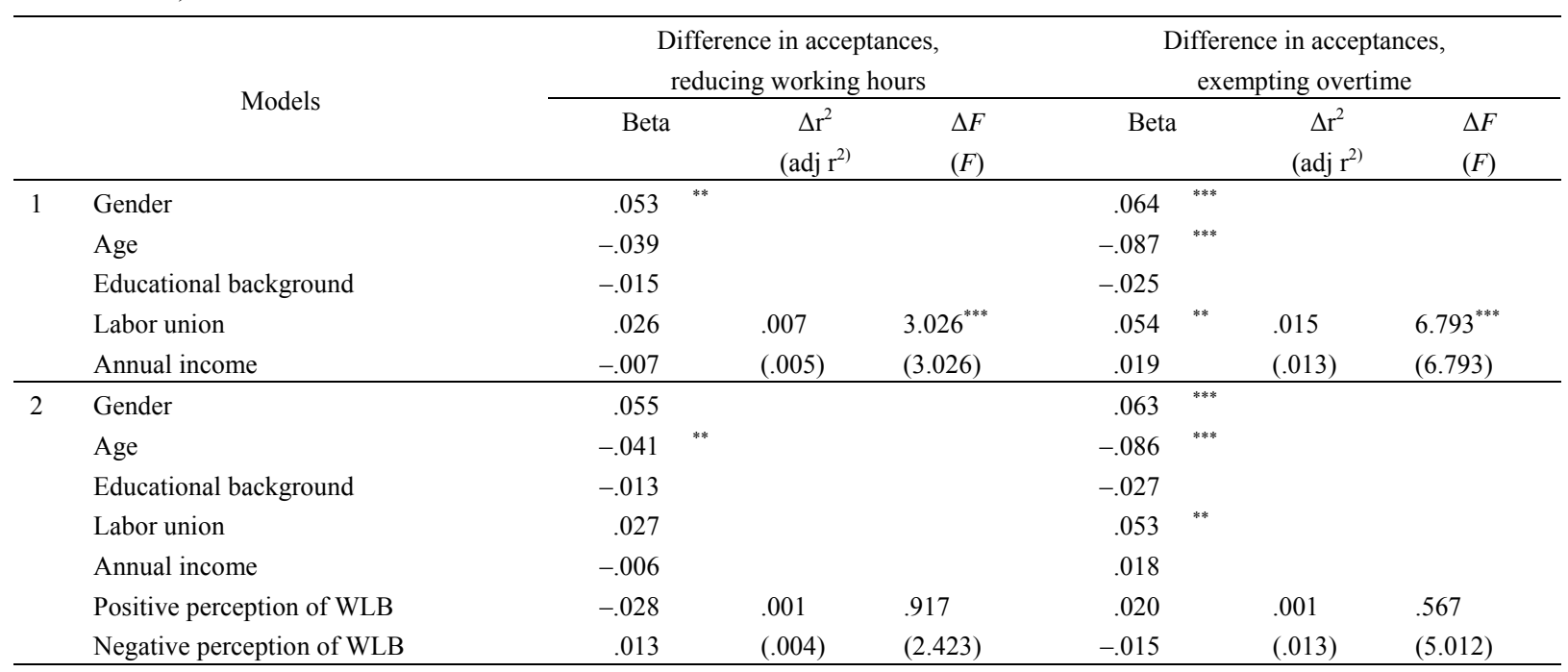

Note: $\mathrm{N}=2,230,{ }^{* * *}: \mathrm{p}<.01,{ }^{* *}: \mathrm{p}<.05,{ }^{*}: \mathrm{p}<.1$.

\section{Discussion and Conclusion}

This article focused on supervisors' responses to their subordinates' work arrangement requests. In accordance with our hypotheses (H1 and H2), supervisors' positive (or negative) perception of WLB was found to have a positive (negative) significant impact on their willingness to accept their subordinates' work arrangement requests. Further, high performers were more likely to receive willing acceptance for their requests from their supervisor than low performers, in support of $\mathrm{H} 3$.

As already discussed, this aspect of supervisory social support is very important for allowing employees to more confidently request improvements in their WLB. Further, supervisory social support appears to be particularly crucial in a high context cultural society like Japan. In fact, it is common for Japanese people to differentiate between honne and tatemae in their relationships. Honne refers to one's true intentions, while tatemae refers to what one says at a surface, social level. Japanese society is often said to be a high context society, where its culturally homogeneous people can understand how they must behave, even if nobody explicitly explains it to them. Yoshimura and Anderson (1997) have also stated, "doing something the right way is more important to the Japanese than is achieving a favorite outcome" (Yoshimura \& Anderson, 1997, p. 51), when they argued the difference between tatemae and honne. When organizations encourage employees to utilize its WLB policy, it often constitutes tatemae, as practical WLB programs based on the organization's WLB policy are usually introduced without consideration for the individual. While it is true that employees have the right to use WLB programs, their surrounding coworkers' honne likely reflects an attitude that each employee has to consider the effects of his or her decision on the workplace community as a whole, to ensure it is not disrupted.

Further, perhaps one of the most difficult problems in Japanese social interaction is that honne is almost never explicitly discussed in formal society such as the workplace, and Japanese employees are required to understand it even when nobody overtly mentions it. Supervisors' willingness belongs to the domain of honne in Japanese culture; therefore, it is important for employees working in a high context society to understand how willingly their supervisors might accept their request, and what factors influence that willingness.

Although this study focused on one of the important topics concerning WLB that has received little attention 
from researchers, it has several limitations that must be improved in future studies. First, there should be a wider range of work arrangements studied. While this study dealt with two different specific requests from subordinates, and found similar effects regardless of the request, both are still associated with working time arrangement. Supervisors might respond to subordinates' requests in different ways depending on the nature of the request, as the impact of that request on the workplace as a whole will differ depending on what is asked. Future studies should examine the subtle differences in supervisors' treatment of their subordinates' various requests regarding WLB utilization.

Secondly, due to the limitations of our data, it was not statistically confirmed whether there was a complicated interaction effect of supervisors' perception of WLB policy and subordinates' performance on supervisors' acceptance. We used secondary data that were collected under a different research objective, but future studies are expected to collect data more appropriate for the studied objective.

\section{References}

Amilton, A. (2010). The temporary leave dilemma: Lone and partnered mothers in Sweden. Feminist Economics, 16(4), 33-52. http://dx.doi.org/10.1080/13545701.2010.530604

Bowling, N. A., Beehr, T. A., \& Swader, W. M. (2005). Giving and receiving social support at work: The roles of personality and reciprocity. Journal of Vocational Behavior, 67(3), 476-489. http://dx.doi.org/10.1016/j.jvb.2004.08.004

Caster, W. J., Harris, C., Taylor-Bianco, A., \& Wayne, J. H. (2011). Work-family conflict, perceived supervisor support and organizational commitment among Brazilian professionals. Journal of Vocational Behavior, 79(3), 640-652. http://dx.doi.org/10.1016/j.jvb.2011.04.011

de Villiers, J., \& Kotze, E. (2003). Work-life balance: A study in the petroleum industry. SA Journal of Human Resource Management, 1(3), 15-23.

Matsuda, Y., Kokumai, M., \& Wang, J. (2009). Reports on survey for work-life balance in Japanese companies (in Japanese). Okayama Economic Review, 41(2), 55-76.

Matthews, R. A., Bulger, C. A., \& Barnes-Farrell, J. L. (2010). Work social supports, role stressors, and work-family conflict: The moderating effect of age. Journal of Vocational Behavior, 76(1), 78-90. http://dx.doi.org/10.1016/j.jvb.2009.06.011

Michael, J. S., Mitchelson, J. S., Pichler, S., \& Cullen, K. L. (2010). Clarifying relationships among work and family social support, stressors, and work-family conflict. Journal of Vocational Behavior, 76, 91-104. http://dx.doi.org/10.1016/j.jvb.2009.05.007

Muse, L. A., \& Pichler, S. (2011). A comparison of types of support for lower-skill workers: Evidence for the importance of family supportive supervisors. Journal of Vocational Behavior, 79(3), 653-666. http://dx.doi.org/10.1016/j.jvb.2011.04.005

Rani, S., Kamalanabhan, \& Selvarani. (2011). Work/life balance reflections on employee satisfaction. Serbian Journal of Management, 6(1), 85-96. http://dx.doi.org/10.5937/sjm1101085R

Sakazume, H. (2009). The effect of front-line manager's perception of the work-life balance practice on leadership behaviors (in Japanese). Japanese Journal of Administrative Science, 22(3), 205-221. http://dx.doi.org/10.5651/jaas.22.205

Schirmer, L. L., \& Lopez, F. G. (2001). Probing the social support and work strain relationship among adult workers: Contributions of adult attachment orientations. Journal of Vocational Behavior, 59(1), 17-33. http://dx.doi.org/10.1006/jvbe.2000.1777

Seiger, C. P., \& Wiese, B. S. (2009). Social support from work and family domains as an antecedent of moderator of work-family conflict. Journal of Vocational Behavior, 75(1), 26-37. http://dx.doi.org/10.1016/j.jvb.2009.03.001

Thomas, L. T., \& Ganster, D. C. (1995). Impact of family-supportive work variables on work-family conflict and strain: A control perspective. Journal of Applied Psychology, 80(1), 6-15. http://dx.doi.org/10.1037/0021-9010.80.1.6

Van Daalen, G., Willemsen, T. M., \& Sanders, K. (2006). Reducing work-family conflict through different sources of social support. Journal of Vocational Behavior, 69(3), 462-476. http://dx.doi.org/10.1016/j.jvb.2006.07.005

Waters, L. (2004). Protégé-mentor agreement about the provision of psychosocial support: The mentoring 
relationship, personality and, workload. Journal of Vocational Behavior, 65(3), 519-532. http://dx.doi.org/10.1016/j.jvb.2003.10.004

Watts, J. H. (2009). 'Allowed into man's world' meaning of work-life balance: Perspectives of women civil engineers as 'minority' employees in construction. Gender, Work and Organization, 16(1), 37-57. http://dx.doi.org/10.1111/j.1468-0432.2007.00352.x

Yoshimura, N., \& Anderson, P. (1997). Inside the Kaisha: Demystifying Japanese Business Behavior. Boston, MA: Harvard Business School Press. 